\title{
Photocatalytic degradation of textile dyes by hydrogel supported titanium dioxide nanoparticles
}

\author{
Harikumar PS ${ }^{1 *}$, Litty Joseph ${ }^{2}$ and Dhanya $\mathrm{A}^{3}$ \\ *Correspondence: drpshari@yahoo.co.in \\ 'Scientist E 2 \& Head, ${ }^{2}$ Junior Research Fellow, ${ }^{3}$ M.tech student, Water Quality Division, Centre for Water Resources \\ Development and Management, Kozhikode, Kerala, India.
}

\begin{abstract}
Background: Textile industry has been condemned as one of the world's worst offenders in terms of pollution because $10-15 \%$ of all the dyes used in the industry are lost within wastewater during processing. The presence of even very low concentrations of dyes in effluent is highly visible and degradation products of these textile dyes are often carcinogenic. Owing to the complex nature of synthetic dyes, conventional biological treatment methods are ineffective. Hence there exist needs for developing treatment techniques that can lead to the complete destruction of the dye molecules from waste stream. The current study focused to develop a new photocatalytic reactor using immobilized $\mathrm{TiO}_{2}$ capacity to decolourise and degrade textile industry effluent in an effective way.

Methods: $\mathrm{TiO}_{2}$ nanoparticles synthesized by simple precipitation method at $\mathrm{pH} 5$ was successfully entrapped in biopolymer calcium (Ca)-alginate and used as heterogeneous photocatalyst for the degradation of various textile dyes using UV radiations. Photocatalyst was characterized by scanning electron microscopy (SEM) and energy dispersive spectroscopy (EDS). The influence of previous operational parameters on the photodegradation has been studied by setting up a laboratory scale photocatalytic reactor.

Results: The scanning electron microscopic images indicate that, the alginate gel acts as a bridge that binds the nanoparticles together. The experimental results showed that the rate of degradation depends on the chemical structure of different dyes as well as adsorption of dyes by $\mathrm{TiO}_{2}$ which is directly proportional to the surface area and dispersion of the catalyst, the adsorption of light by the dye. The kinetics of COD disappearance was slower than the discoloration of the solution. The supported $\mathrm{TiO}_{2}$ can be used several times without lose of efficiency

Conclusions: The results of this study have shown that the degradation of different textile dyes was successfully carried out in laboratory scale photoreactor containing coated $\mathrm{TiO}_{2}$ as photo catalyst. Calcium alginate can be used as a green support for immobilizing $\mathrm{TiO}_{2}$ nanoparticles and can be used for developing a new environment friendly immobilization system for large scale water treatment.
\end{abstract}

Keywords: Immobilized $\mathrm{TiO}_{2}$ nanoparticles, photocatalytic degradation, textile dyes

\section{Background}

Wastewater from textile industries poses a threat to the environment as large amount of chemically different dyes are used for various industrial applications and a significant proportion of these dyes enter the environment via wastewater. Around $10-15 \%$ of all the dyes used in the industry are lost within wastewater during synthesis and processing [1]. Due to its complex chemical structure, dye is one of the most difficult constituents in textile wastewater to treat [2]. The presence of even very low concentrations of dyes in effluent is highly visible and degradation products of these textile dyes are often carcinogenic [3]. Many dyes are visible in water at concentrations as low as $1 \mathrm{mgL}^{-1}$. Textile processing wastewaters, typically with dye content in the range $10-200 \mathrm{mgL}^{-1}$ [4] are therefore usually highly coloured and discharge in open waters presents an aesthetic problem. The treatment of textile effluents is of interest due to their toxic and aesthetical impacts on receiving waters. Treating wastewater before it is discharged to the natural water bodies reduces the risks posed to human and environmental health [5].

There are more than 10,000 commercially available dyes with over $7 \times 10^{5}$ tones of dyestuff produced annually across the world [6]. With the increased use of a wide variety of dyes, pollution by dye's wastewater is becoming increasingly alarming. Most of the dyes used in the textiles industries are stable to light and non biodegradable [7]. In order to reduce the risk of environmental pollution from such wastewater, it is necessary to treat them before discharging it into the environment [8]. Physical and chemical processes has been usually used to treat the wastewater. However these processes are costly and cannot be used effectively to treat the wide range of dye wastewater $[\mathbf{9 , 1 0 ]}$. Adsorption is a useful and simple technique which has gain considerable attention in the recent few years [11]. However, these systems merely 
transfer the dye from one form of waste to another (e.g, liquid to solid), and, therefore, cannot be considered to be a complete treatment of the waste [12]. In recent years great efforts have been made using widely called advance oxidation technologies (AOT) for treatment of these recalcitrant pollutants to more biodegradable molecules. The generation of reactive species like hydroxyl radicals is the basis for AOPs. These radicals can attack most of the organic molecules with rate constant usually in the range of $106-109 \mathrm{M}^{-1} \mathrm{~S}^{-1}$ [13]. Among the many processes proposed and being developed to destroy water soluble organic pollutants in water and wastewater one of the most important oxidation processes is heterogeneous photocatalysts via combination of $\mathrm{TiO}_{2}$ and light [14]. $\mathrm{TiO}_{2}$ is a commonly used photo-catalyst because of its stability in UV light and water. $\mathrm{TiO}_{2}$ can function as both an oxidative and reductive catalyst. $\mathrm{TiO}_{2}$ is considered very close to an ideal semiconductor for photocatalysis because of its high strong oxidizing power, non toxicity and long term photostablility [15]. Some challenges in $\mathrm{TiO}_{2}$ photocatalysis, including enhancement of the catalytic activity, controllability of the structural properties, immobilization to form films and membranes and narrowing of the band gap energy, could be solved by introducing nanotechnological synthesis routes, noble material processing approaches, and new reactor design and concepts. Nanoscale particles are promising in this area because of their unique properties such as small particle sizes, large surface to volume ratio and the ease with which they can be anchored onto the solid matrices for enhanced treatment of water, wastewater [16]. $\mathrm{TiO}_{2}$ nanoparticles have unique properties of small size, larger special surface area, stronger magnetism, photocatalyst, well-UV absorption, surface activity, heat-conductance, disperse property. However, the obligation to separate the small $\mathrm{TiO}_{2}$ particles from the suspension after treatment limits the process development.

The key problem of industrializing the technology seems to be its time consuming and expensive process of separation and recycling. The above problems can be avoided by immobilization of the photocatalyst over suitable supports. Systems which incorporate immobilization on a solid surface are most popular due to their relative ease implementation [17]. Although entrapment is one of the simplest methods used for cells and enzymes immobilization that can be adapted for $\mathrm{TiO}_{2}$ immobilization also. This method consists in the inclusion of these species within polymeric matrices [18]. Biodegradable polymer materials will reduce the need for synthetic polymer and will results in production at a low cost, thereby producing a positive effect both environmentally and economically. Calcium alginate is a biocompatible and mechanically stable gel. Moreover, alginate is nontoxic, biodegradable, and non immunogenic, and produces thermally irreversible and water insoluble gels [19]. Therefore Calcium alginate can be used as a green support for $\mathrm{TiO}_{2}$ immobilization that can be used for developing a new environmentally friendly immobilization system for large scale water treatment. The main objective of this work is to develop a photocatalytic reactor using immobalized $\mathrm{TiO}_{2}$ nanoparticles with high photocatalytic activity in the removal of contaminants from textile industry. In the present work, the photocatalytic degradation of some dyes having different chemical structures (azo, anthraquinone and reactive dye) on laboratory scale photo catalytic reactor with immobalized $\mathrm{TiO}_{2}$ nanoparticles as photocatalyst has been investigated.

\section{Methods}

\section{Synthesis of $\mathrm{TiO}_{2}$ Nanoparticles}

Chemical precipitation method was adopted to synthesize $\mathrm{TiO}_{2}$ nanoparticles in this work. $\mathrm{TiCl}_{3}$ (MERCK 15\%) solution in $\mathrm{HCl}(10-15 \%)$ was introduced under vigorous stirring in deionized water $\left(\left[\mathrm{Ti}^{3+}\right]=0.15 \mathrm{~mol} \mathrm{~L}^{-1}\right)$. A blue-violet solution was obtained at room temperature. The $\mathrm{pH}$ was adjusted between 2.5 and 5.0 with sodium hydroxide $(\mathrm{NaOH})$ solution. The solutions were then heated at $60^{\circ} \mathrm{C}$ in an oven for $24 \mathrm{~h}$. The white suspension obtained were then centrifuged, washed with an acidic solution $(\mathrm{pH}=1)$ and distilled water in order to remove salts. Solid nano $\mathrm{TiO}_{2}$ was prepared by drying the suspension in an oven at a temperature of $120^{\circ} \mathrm{C}$ for 12 hour and calcined in a muffle furnace at $450^{\circ} \mathrm{C}$ for 3 hour.

\section{Immobilization on biopolymer-Calcium Alginate}

In the present work, we attempted to use a new support for immobilization of nanoparticles for the purpose of water treatment. We used one step encapsulation method for immobilization of nanoparticles in semi permeable alginate beads. Sodium-Alginate manufactured by Hi-Media Laboratories Pvt. Ltd was used for this study. A solution containing $\mathrm{TiO}_{2}$ nanoparticles $(2.0 \mathrm{wt} \%$ ) and sodium alginate (2.0 wt \%) was prepared with distilled water, and stirred for $30 \mathrm{~min}$ at $85^{\circ} \mathrm{C}$. Afterwards, the solution was extruded as small drops by means of syringe into a stirred solution of calcium chloride ( $8.0 \mathrm{wt} \%)$, where spherical gel beads were formed with a size of 2-3 $\mathrm{mm}$. The gel beads were retained in the $\mathrm{CaCl}_{2}$ solution for $12 \mathrm{~h}$ for hardening and then washed with distilled water. The excess water in the beads was removed by blotting with filter paper [20]. Stability of alginate beads were studied using concentrated and diluted solutions of hydrochloric, nitric and sulphuric acids and sodium and potassium hydroxides. Stability of beads depends on $\mathrm{pH}$ values of the aqueous solutions and the initial physical state of the beads. These beads were used for further photocatalytic studies.

\section{Characterization of Photo-catalyst}

The characterization of nanoparticles was done using UV-spectrophotometer and SEM/EDS. 




UV-Visible spectrophotometer

Evolution 201 UV-Visible Spectrophotometer (Thermo Scientific, USA) was used for the characterization of $\mathrm{TiO}_{2}$ nano particles. The instrument has a scanning speed up to $6000 \mathrm{~nm} / \mathrm{min}$ and has a wavelength range between $190-1100 \mathrm{~nm}$.

\section{SEM/EDS: Scanning Electron Microscopy with X-ray microanalysis}

The size and shape of the nano- and submicro-particles was examined with a Field Emission scanning electron microscope equipped with Horiba EDX analyser, made by Hitachi (SU-6600). It utilizes advanced Variable Pressure (VP) technology and an improved Schottky field emission electron source that provides exceptional imaging and high probe current with great stability in both high vacuum and variable pressure operation. SEM images were observed with a magnification of $2.00 \mu \mathrm{m}$ with an accelerating voltage of $15.0 \mathrm{kV}$.

\section{Experimental Set Up}

The experimental set up consists of an ultraviolet light source, electronic ballast and an aluminum column of length $20 \mathrm{~cm}$ and diameter $15 \mathrm{~cm}$. The ultraviolet light source used was mercury vapor lamp of predominant wavelength $292.3 \mathrm{~nm}$ developed by Philips Lighting. The UV source can be described as tube light reactor (TLR) operated at 60V, and produced $9 \mathrm{~W}$. This lamp is placed inside the reactor. Electrical wires were connected to the lamp through copper holders that are screwed around the lamps end. The $\mathrm{TiO}_{2}$ nanoparticle immobilized in calcium alginate which was in the form of spherical beads, were used as the catalyst. $100 \mathrm{gm}$ beads containing $\mathrm{TiO}_{2} 2 \% \mathrm{wt}$ were used in this experiment. It was filled uniformly on the outer surface of the low wattage lamp so as to provide a higher illuminated specific catalyst surface area than even a slurry reactor. The photo catalytic reactor was fixed as vertical hung. The experimental set up of the photocatalytic reactor is as shown in Figure 1. The photocatalytic reactor is vertically hunged on the stand. The initial dye solutions were passed through the inlet port of the photocatalytic reactor and the treated solutions were taken out through the outlet port of the photocatalytic reactor.

\section{Photo catalytic Studies}

The photo catalytic activity of $\mathrm{TiO}_{2}$ nanoparticles on the degradation of the synthetically prepared effluents and industrial effluent was evaluated in laboratory conditions under illumination of UV light in the photoreactor. Stock solutions of anthraquinone dye and azo dye were prepared by dissolving the requisite quantity of each dye in distilled water without further purification. The dyes used were Methyl Orange, Methyl Red from MERCK and Alizarin Red $S$ from LOBA chemicals. Real time effluents from the field were collected from two local dyeing industries. Methyl orange is a stable azo dye, hence it was used for the experiments. Effluent collected from ACR textiles, Kannur consists of a mixture of three reactive dyes namely Red SB, Blue SG, Yellow S3R, NaCl and Soda ash. Similarly effluent collected from Co-operative weaver's society, Kozhikode consisted of vat dyes. The dye solutions were introduced to the inlet of the photoreactor and at different time intervals the treated effluent was withdrawn from the outlet of the reactor. All experiments were carried out under ambient conditions i.e., at room temperature and $1 \mathrm{~atm}$.

\section{Degradation studies of the dye solutions}

The photocatalytic activity of $\mathrm{TiO}_{2}$ nanoparticles on the dye solutions were determined by measuring the absorbance of the dye solutions before and after the treatment, determining the COD of the dye solutions before and after the treatment, FTIR analysis of the dye solutions before and after the treatment.

\section{UV Spectra}

The absorbance of the prepared dye solutions and the effluents collected were measured before and after degradation at different degradation times. Measurements were carried out using Evolution 201 UVVisible Spectrophotometer in the photon energy range of wavelength from 200 to $600 \mathrm{~nm}$. The colour removal of the dye solution was measured at the $\lambda$ maximum of the absorption spectrum of each dye. Decolorization efficiency was calculated from a mathematical equation adapted from measurements of decolorization. From the respective absorbances obtained, percentage color 

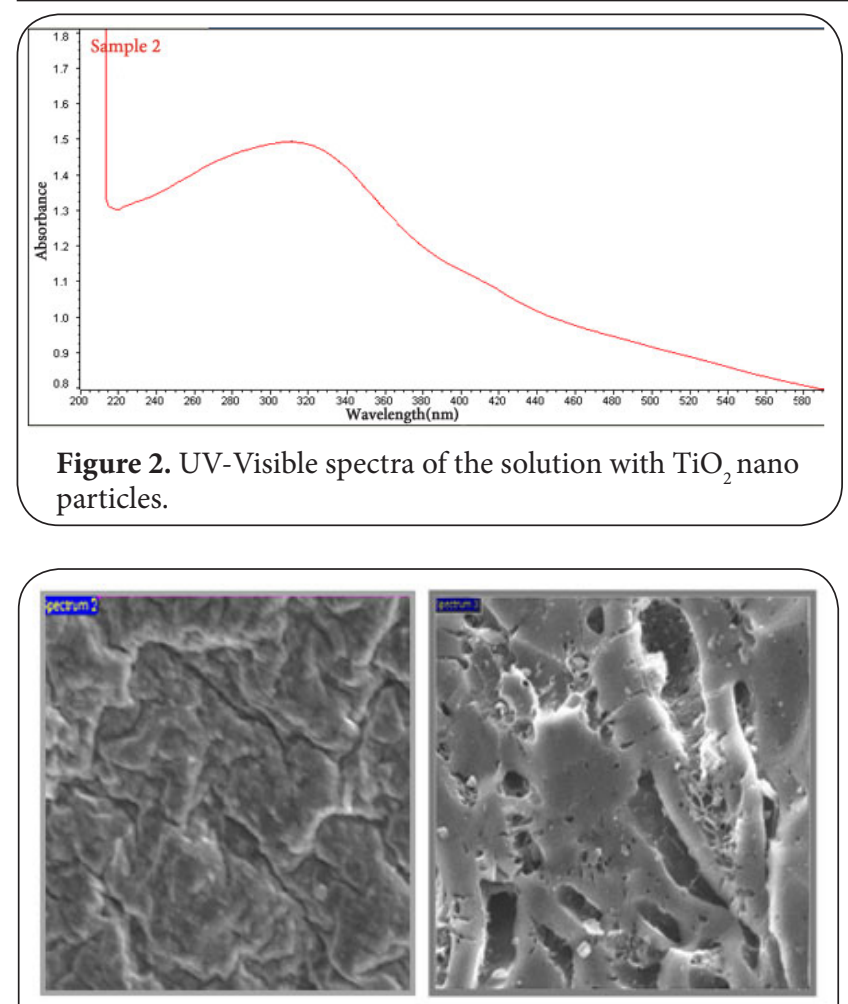

Figure 3. SEM image of $2 \% \mathrm{TiO}_{2}$ nanoparticles entrapped Alginate beads at different magnification.

disappearance was calculated using the following:

$$
\text { Decolorization \% }=\frac{(\text { Absorbance })_{0}-(\text { Absorbance })_{t}}{(\text { Absorbance })_{0}} \times 100
$$

Where (Absorbance) ${ }_{0}$ is the absorbance before irradiation and (Absorbance) ${ }_{t}$ is the absorbance at time $t$.

\section{Chemical Oxygen Demand (COD)}

To investigate the biodegradability of the dye solutions, COD analysis was done by the standard acid dichromate method. COD measurement before the treatment and after the treatment with the photocatalyst is used as a measure of mineralization of the dye solutions. The photodegradation efficiency of the different dye solutions were calculated .

\section{FTIR analysis}

Degradation of the dye solutions was confirmed with IR spectroscopy which involves collecting absorption information and analyzing it in the form of a spectrum. FTIR spectrum was used as a measure to confirm the degradation of textile effluent. Measurements were carried out using Bruker Alpha Spectrophotometer, utilizing the ATR (Attenuated Total Reflection) FT-IR sampling technique.

\section{Effect of $\mathrm{pH}$ and ions}

In the real effluents, the dyes are present with many organic and inorganic species that can affect the photocatalytic degradation. The effluent $\mathrm{pH}$ may vary according to the type of dyes used. Therefore study of $\mathrm{pH}$ is an important parameter in the degradation of dyes. The effect of $\mathrm{pH}$ was studied by adjusting the $\mathrm{pH}$ value to different range by addition of $\mathrm{HNO}_{3}(1 \mathrm{~N})$ and $\mathrm{NaOH}(1 \mathrm{~N})$. Similarly, the effects of various ions were investigated using (100ppm) solutions of chloride, sulphate, nitrate and phosphate prepared using $\mathrm{NaCl}, \mathrm{KNO}_{3}, \mathrm{NaH}_{2} \mathrm{PO}_{4}$ and $\mathrm{K}_{2} \mathrm{SO}_{4}$ respectively. All chemicals used were purchased from $\mathrm{E}$ MERCK India.

\section{Recycling of Photocatalyst}

The catalyst's lifetime is an important parameter of the photocatalytic process, due to the fact that its use for a longer period of time leads to a significant cost reduction of the treatment. For this reason, the catalyst was recycled four times. After the optimized conditions for the degradation of the effluent were determined, the catalyst was recovered by giving acid wash using dil. $\mathrm{HCl}$ and hot water and again used to study its recyclability.

\section{Results and discussion}

Preparation and Characterisation of Photocatalyst Chemical precipitation method was adopted to synthesize $\mathrm{TiO}_{2}$ nanoparticles. In the precipitation method, the first product precipitated at $\mathrm{pH} 3$ was a mixture of anatase and rutile. By increasing the $\mathrm{pH}$ of the solution, the formation of anatase was favored and at $\mathrm{pH}$, only anatase $\mathrm{TiO}_{2}$ could be formed [21]. The formation of nanoscale $\mathrm{TiO}_{2}$ at $\mathrm{pH} 5$ was confirmed by UV and EDAX examination of the product. The room temperature absorption spectrum of the $\mathrm{TiO}_{2}$ nanoparticles is shown in Figure 3. $\mathrm{TiO}_{2}$ exhibited larger absorption in the visible light region with an onset absorption band at $280-400 \mathrm{~nm}$ The absorption spectrum of $\mathrm{TiO}_{2}$ at $400 \mathrm{~nm}$ is due to the charge transfer from the valence band (mainly formed by $2 p$ orbitals of the oxide anions) to the conduction band (mainly formed by $3 \mathrm{~d} \mathrm{t}_{2 \mathrm{~g}}$ orbitals of the $\mathrm{Ti}^{4+}$ cations) [22]. The obtained result showed a strong, but broad peak located at a range $290-400 \mathrm{~nm}$ (Figure 2).

$\mathrm{TiO}_{2}$ nanoparticles were then entrapped in a biopolymer for studying its photo catalytic degradation of textile dyes. Ca-Alginate was used as the solid support in this work. Calcium alginate beads in diluted acidic and alkaline solutions were mechanically stable. But gel beads in strong acidic solutions, tends to shrink and completely dissolve in concentrated solutions of sodium and potassium hydroxides after 3 days. This may be due to the ion-exchange process taking place between $\mathrm{Na}^{+} / \mathrm{K}^{+}$ions in solution and $\mathrm{Ca}^{2+}$ ions in the beads. SEM study was carried out to confirm the size of the particles, and its distribution pattern in polymeric matrix. A representative SEM image in Figure 3 shows that most of the particles are well distributed. The particle size of the samples estimated from the SEM micrographs was below $50 \mathrm{~nm}$. The quantitative compositional analysis of the $\mathrm{TiO}_{2}$ nanoparticle entrapped beads was carried 




Figure 4. EDX spectrum of $\mathrm{TiO}_{2}$ nanoparticles entrapped Calcium Alginate beads.

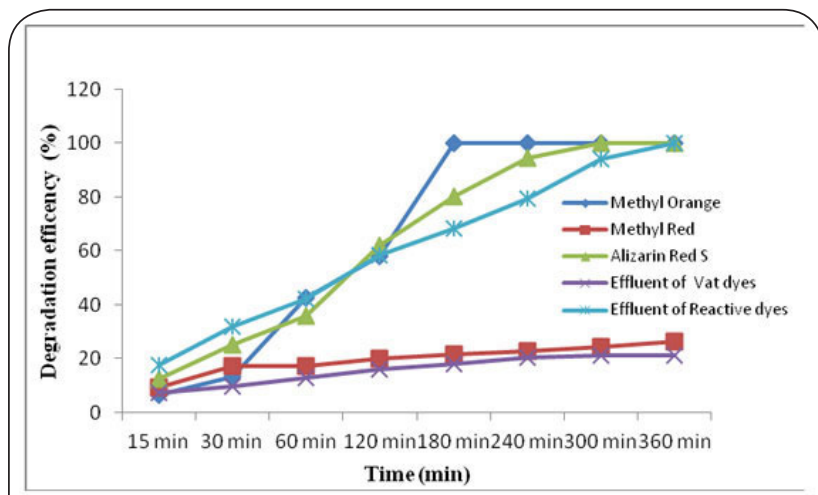

Figure 5. Kinetics curves of colour disappearance for the five dyes.

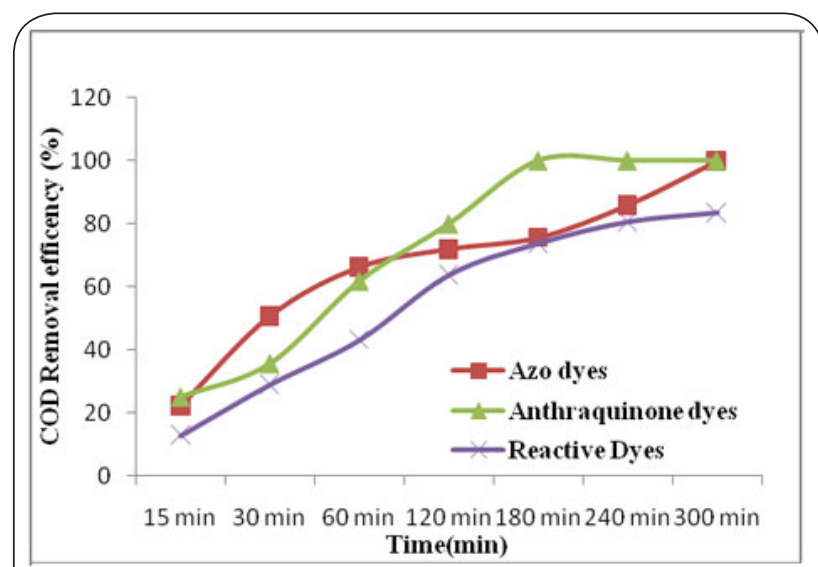

Figure 6. Kinetics curves of COD disappearance for the three dyes.

out using energy dispersive X-ray (EDAX) spectroscopy measurements. The spectra confirm the presence of $\mathrm{TiO}_{2}$ in the structure, as shown in Figure 4. The spectra were recorded from a single bead. From the measurements, it is enumerated that the each bead consist of an average
$5.48 \% \mathrm{Ti}, 16.76 \% \mathrm{O}_{2}, 14.82 \% \mathrm{Ca}, 10.18 \% \mathrm{Na}$ and $48.83 \% \mathrm{Cl}_{2}$. EDS analysis showed no significant levels of impurities which could have originated from the process.

\section{Photocatalytic studies}

An understanding of reaction rates and how the reaction rate is influenced by different parameters is important for the design and optimization of an industrial system. The rate of photocatalytic degradation depends on several factors including illumination intensity, catalyst type, oxygen concentration, $\mathrm{pH}$, presence of inorganic ions and the concentration of the organic reactant. The efficiency of photocatalytic activity of $\mathrm{TiO}_{2}$ nanoparticles on the dye solutions were determined by measuring the absorbance of the dye solutions before and after the treatment, determining the COD of the dye solutions before and after the treatment, FTIR analysis of the dye solutions before and after the treatment.

\section{Absorbance Measurements}

Figure 5 shows the trend of gradual decomposition of the five dyes which was monitored by measuring the absorbance at regular intervals. It was noticed that among these 5 dyes, Methyl orange, suffers degradation with the higher rate than the others. The efficiency reached only around $25.5 \%$ after 5 hours in the case of methyl red and vat dyes. Control experiments, using UV irradiation in the absence of catalyst, showed no loss of colour after 60 minutes exposure, confirming the critical role played by the $\mathrm{TiO}_{2}$ catalyst in dye degradation. The apparatus was found to be not much effective in case of liquor dying. Further studies were not carried out in the case of such dyes.

\section{Effect of irradiation time on COD}

The efficiency of photocatalytic treatment to mineralize three types of dyes was investigated. The percentage of COD removal efficency has been ploted as a function of irradiation time (Figure 6). It is interesting to remark that the COD decreases slower than the discoloration of the solution. At 180 minutes the colour degradation efficiency observed was 100, 80 and $68 \%$ respectively for azo dye, antharaquinone dye and reactive dye. But COD removal efficiency at 180 minutes was found to be 76,100 and $73 \%$ respectively. This result can be explained due to the fact the dyes are not directly mineralized, but transformed in intermediate photoproducts. After total discoloration of the dye solutions, there still remain traces of COD (20 to $30 \%)$. This means that the discoloration can enhance the aesthetic quality of water, rather than the total purification and detoxification.

\section{FTIR Analysis}

The FTIR spectra of control Methyl orange (Figure 7a), displays peak at 2,924.06 $\mathrm{cm}^{-1}$ for asymmetric $\mathrm{CH}_{3}$ stretching vibrations; peaks at $1,519.78$ and $1,421.71 \mathrm{~cm}^{-1}$ for the 


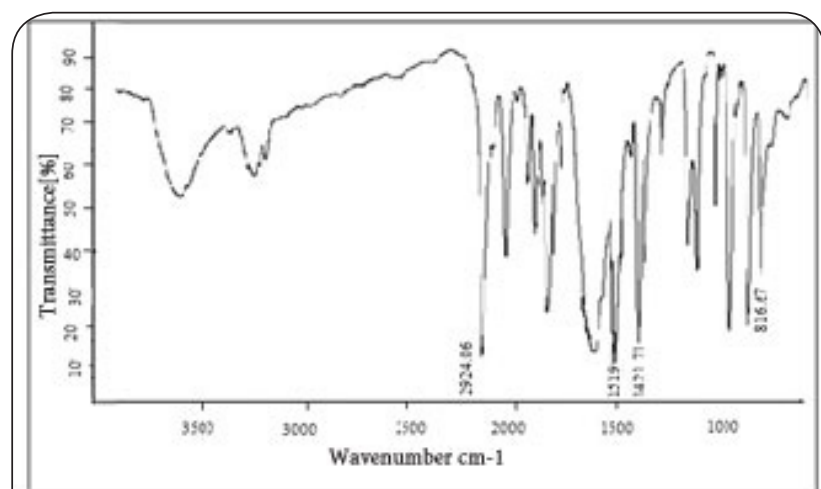

Figure 7a. FTIR Spectra of Initial solution of Methyl Orange.

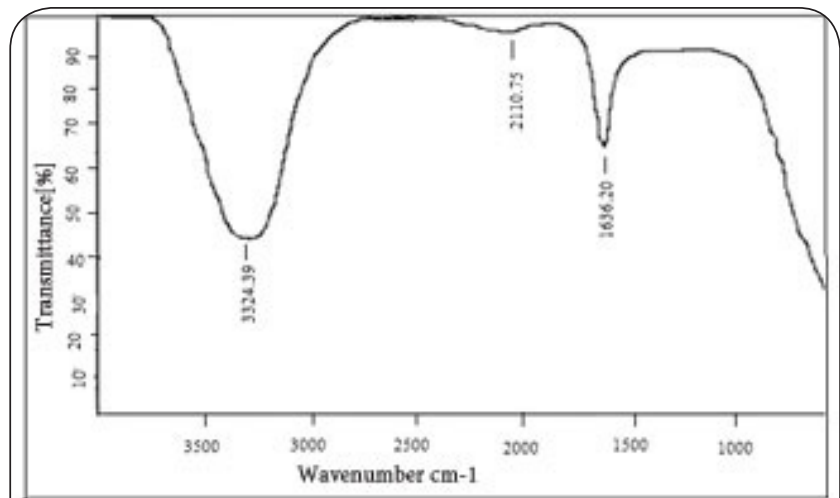

Figure 7b. FTIR Spectra of Methyl Orange solution after 180 min treatment.

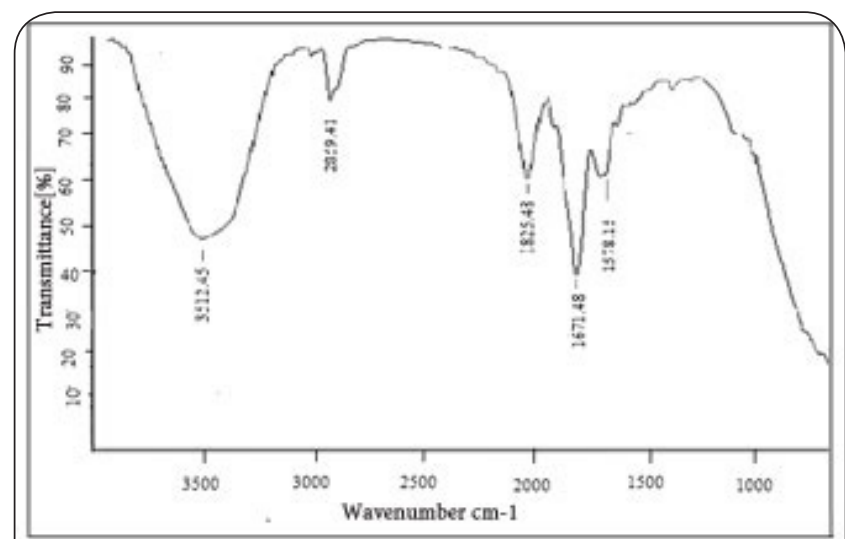

Figure 8a. FTIR Spectra of Initial solution of Alizarin Red S.

$\mathrm{C}=\mathrm{C}-\mathrm{H}$ in plane $\mathrm{C}-\mathrm{H}$ bend; peaks at $1,040.00,1,007.29$, and $846.66 \mathrm{~cm}^{-1}$ for ring vibrations; and a peak at $816.67 \mathrm{~cm}^{-1}$ for the1, 4 disubstituted (Para) benzene ring. All these peaks confirm the aromatic nature of the dye. But in Figure $\mathbf{7 b}$ the peaks at $1600-1400 \mathrm{~cm}^{-1}$ which indicates aromatic $\mathrm{C}=\mathrm{C}$ bond and Phenyl ring Substitution band due to $\mathrm{C}-\mathrm{H}$ at $870-675 \mathrm{~cm}^{-1}$ was entirely absent. The FTIR spectrum of the degradation products formed by photocatalyic degradation had displayed entirely new peaks compared to the initial control dye, which confirms the degradation

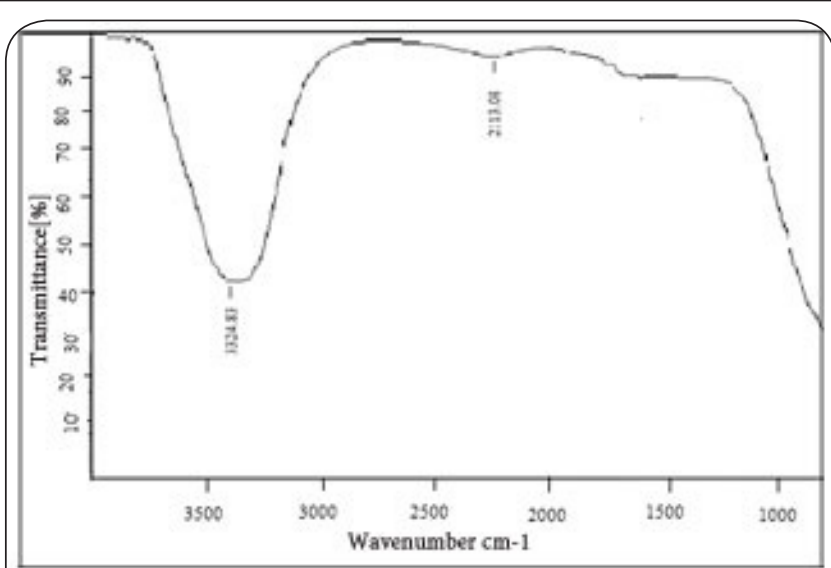

Figure 8b. FTIR Spectra of Alizarin Red S after treatment.

of Methyl orange. The new peaks at $3324 \mathrm{~cm}^{-1}$ and 1636 $\mathrm{cm}^{-1}$ corresponds to $\mathrm{N}-\mathrm{H}(\mathrm{m})$ stretch and asymmetrical stretch of Nitro compounds. This indicates that $\mathrm{TiO}_{2}$ nanoparticle immobilized in Calcium- Alginate used in the experiment had resulted in the photodegradation of the dye. The FTIR spectra of Alizarin (Figure 8a), displays peak at $1671.48 \mathrm{~cm}^{-1} 1578.15 \mathrm{~cm}^{-1}$ for aromatic $C=C$ bond; peak at $3512.45 \mathrm{~cm}^{-1}$ for the $\mathrm{OH}$ stretch; peak at $1825.48 \mathrm{~cm}^{-1}$ for multiple bonded CO group and 2859.41 $\mathrm{cm}^{-1}$ for the $\mathrm{C}-\mathrm{H}$ stretch. All these peaks confirm the aromatic nature of the dye. But in Figure 5. 16 the peaks at 1600 $\mathrm{cm}^{-1}-1400 \mathrm{~cm}^{-1}$ which indicates aromatic $\mathrm{C}=\mathrm{C}$ bond and $\mathrm{C}=\mathrm{O}$ at $1850 \mathrm{~cm}^{-1}-1650 \mathrm{~cm}^{-1}$ was entirely absent. The FTIR spectrum (Figure $\mathbf{8 b}$ ) of the degradation products formed by photocatalyic degradation had displayed entirely new peaks compared to the initial control dye, which confirms the degradation of Alizarin Red S. The new peaks at $3324.83 \mathrm{~cm}^{-1}$ and $2113.08 \mathrm{~cm}^{-1}$ correspond to $\mathrm{C}-\mathrm{H}$ stretch. This indicates that $\mathrm{TiO}_{2}$ nanoparticle immobilized in Calcium Alginate used in the experiment had resulted in the photodegradation of the dye.

The FTIR spectrum of the degradation products formed by photocatalyic degradation (Figure 9 a) had displayed entirely new peaks compared to the raw effluent (Figure 9b), which confirms the degradation of the dyes in the textile effluent. This indicates that $\mathrm{TiO}_{2}$ nanoparticle immobilized in Calcium Alginate prepared in the experiment had high photocatalytic activity.

\section{Effect of pH}

$\mathrm{pH}$ of the real effluent may vary according to the type of dyes used and the organic and inorganic compounds added to it. Therefore study of $\mathrm{pH}$ is an important parameter in the degradation of dyes. The absorbance of Methyl Orange at $462 \mathrm{~nm}$ and Alizarin at $445 \mathrm{~nm}$ for different $\mathrm{pH}$ is as shown in Figure 10. The absorbance values showed that the photodecolouration efficiency of methyl orange decreased in the order of $\mathrm{pH} 3>\mathrm{pH} 5>\mathrm{pH} 7>\mathrm{pH} 9>$ $\mathrm{pH}$ 11. Such a result can be better understood by taking 


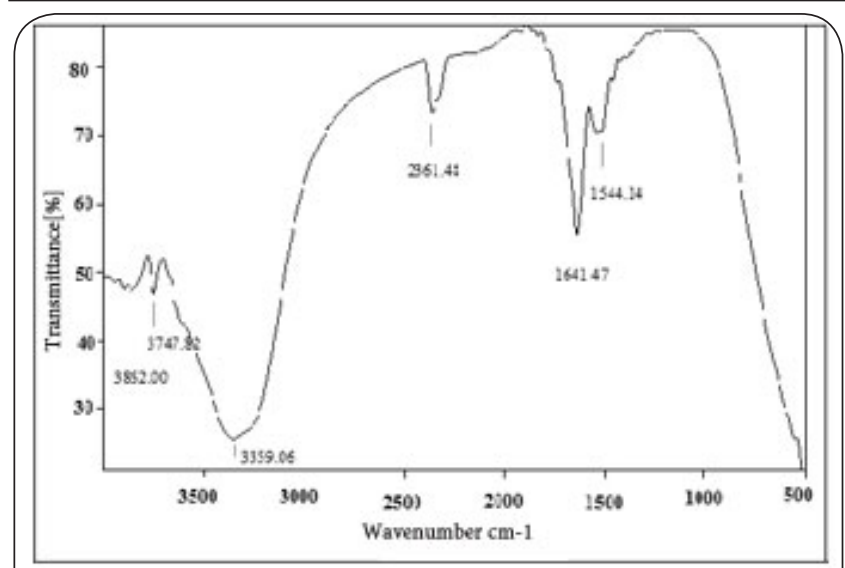

Figure 9a. FTIR Spectra of Initial solution of textile effluent.

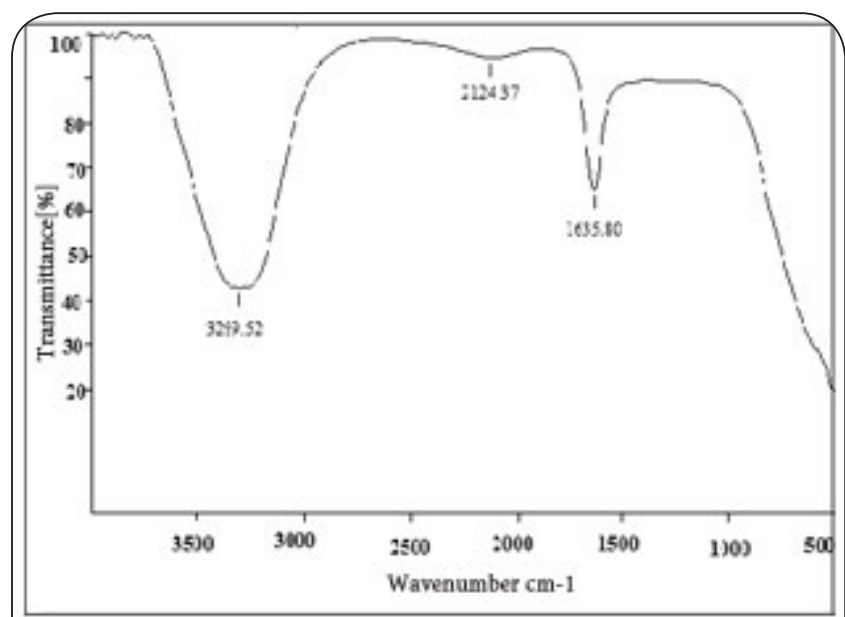

Figure 9b. FTIR Spectra of Initial solution of textile effluent after treatment.

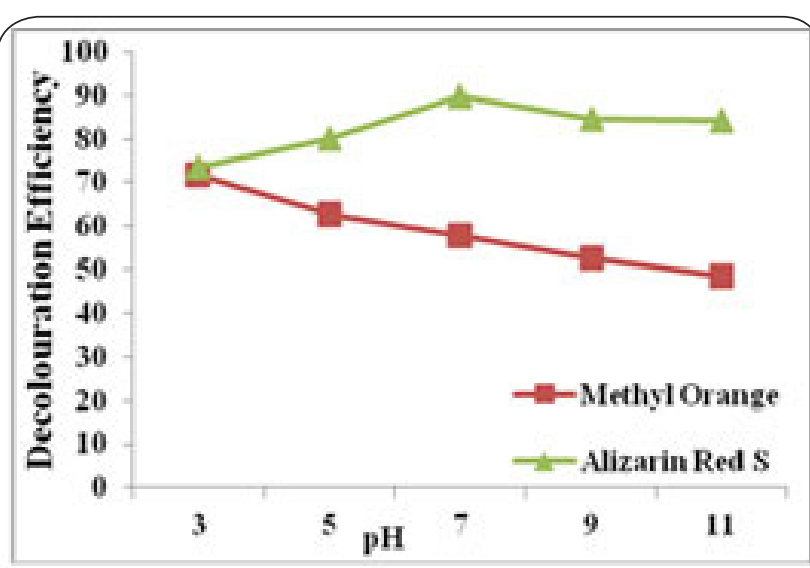

Figure 10. Effect of $\mathrm{pH}$ on Decolouration Efficiency.

account that both the surface state of the photocatalyst and the ionisation state of Methyl Orange depend on the $\mathrm{pH}$ of the solutions. The $\mathrm{pH}$ of zero charge $(\mathrm{pH} \mathrm{pzc})$ of $\mathrm{TiO}_{2}$ is known to be close to $\mathrm{pH}=6.8$ which means that for $\mathrm{pH}$ higher than 6.8 , the surface becomes negatively charged according to the electrochemical equilibrium [23]

$$
\mathrm{TiOH}+\mathrm{OH}^{-} \rightarrow \mathrm{H}_{2} \mathrm{O}+\mathrm{TiO}^{-}
$$

and at $\mathrm{pH}$ lower than $\mathrm{pH}$ pzc, the surface of Titania is positively charged according to

$\mathrm{TiOH}+\mathrm{H}^{+} \rightarrow \mathrm{TiOH}_{2}^{+}$

From the Figure 10, it can be seen that the rate of degradation of methyl Orange decreases for a $\mathrm{pH}$ higher than three, in correlation with the decrease of the amount of $\mathrm{TiOH}_{2}^{+}$. The adsorption at basic $\mathrm{pH}$ is not favoured because repulsive electrostatic force due to predominant $\mathrm{TiO}^{-}$in this range of $\mathrm{pH}$. The photodecolouration efficiency of alizarin increases from $\mathrm{pH} 3$ to $\mathrm{pH} 7$ and then decreases from $\mathrm{pH} 7$ to $\mathrm{pH}$ 11. The reason for increase in efficiency up to $\mathrm{pH} 7$ is due to strong adsorption of the dye on to the $\mathrm{TiO}_{2}$ particles as a result of the electrostatic attraction of the positively charged $\mathrm{TiO}_{2}$ with the ionized dye. A decrease in the reaction rate has been observed, with a minimum at $\mathrm{pH} 11$, reflects the difficulty of anionic dye in approaching the negatively charged $\mathrm{TiO}_{2}$ surface when increasing the solution $\mathrm{pH}$.

\section{Effect of ions}

In the real effluents, the dyes are present with many organic and inorganic species that can affect the photocatalytic degradation. In this study, the effects of various ions were investigated. The effect of ions like chloride, sulphate nitrate and phosphate on the decolouration efficiency was studied and is tabulated in Table 1. The values in the table shows that the presence of $\mathrm{Cl}^{-}, \mathrm{SO}_{4}^{2-}$ and $\mathrm{NO}^{3-}$ anions leads to an increase of the effectiveness of the photo catalytic degradation and the presence of $\mathrm{HPO}^{2-}$ anion decreases the photocatalytic efficiency. This is because in the case of chloride ions the formation of $\mathrm{Cl} \cdot$ radical by the reaction of photo produced $\mathrm{OH}^{\cdot}$ with $\mathrm{Cl}^{-}$oxidizes pollutants results in increase in efficiency of degradation. [24] Similarly the $\mathrm{SO}_{4}^{2-}$ ions adsorbed in the surface of $\mathrm{TiO}_{2}$ react with photo-induced holes $\left(\mathrm{h}^{+}\right)$to form sulphate radical anion $\left(\cdot \mathrm{SO}_{4}^{-}\right)$which is a strong oxidant [25]. The $\mathrm{NO}_{3}^{-}$ions, weakly adsorbed on the surface of $\mathrm{TiO}_{2}$ may cause acidification of the solution with the nitric acid and therefore increase the photocatalytic degradation by decreasing $\mathrm{pH}$. The same interpretation is proposed for $\mathrm{HPO}_{4}^{2-}$ ions which increase the $\mathrm{pH}$ of the solution and consequentlydecrease the photo catalytic degradation.

\section{Recycling of Photocatalyst}

Photocatalyst can be recycled effectively which makes the process cost effective. For this reason, the catalyst was recycled four times as shown in Figure 11. After the optimized conditions for the degradation of Methyl Orange were determined, the catalyst was recovered by giving acid wash and again used to study its recyclability. The obtained results showed that the efficiency decreases from 88 to $54 \%$. This is likely due to the fouling of the 
Harikumar et al. Journal of Environmental Engineering \& Ecological Science 2013, http://www.hoajonline.com/journals/pdf/2050-1323-2-2.pdf

Table 1. Effects of ions on the Photo degradation efficiency.

\begin{tabular}{|c|c|c|c|c|c|c|c|c|}
\hline \multirow[b]{3}{*}{ Dyes } & \multicolumn{8}{|c|}{ Degradation Effeciency } \\
\hline & \multicolumn{2}{|l|}{$30 \mathrm{~min}$} & \multicolumn{2}{|l|}{$60 \mathrm{~min}$} & \multicolumn{2}{|l|}{$90 \mathrm{~min}$} & \multicolumn{2}{|l|}{$120 \mathrm{~min}$} \\
\hline & Methyl Orange & Alizarin Red S & Methyl Orange & Alizarin Red S & Methyl Orange & Alizarin Red S & Methyl Orange & Alizarin Red S \\
\hline Chloride & 24.06 & 42.35 & 53.01 & 69.15 & 58.65 & 74.51 & 72.93 & 88.17 \\
\hline Sulphate & 20.30 & 59.46 & 48.50 & 85.83 & 55.64 & 89.88 & 71.80 & 97.19 \\
\hline Nitrate & 25.56 & 48.38 & 53.76 & 75.14 & 60.53 & 79.10 & 74.43 & 91.56 \\
\hline Phosphate & 10.56 & 30.33 & 36.47 & 48.29 & 36.59 & 56.45 & 59.99 & 71.52 \\
\hline Control & 13.16 & 35.78 & 42.48 & 61.88 & 49.25 & 68.78 & 57.89 & 80.00 \\
\hline
\end{tabular}

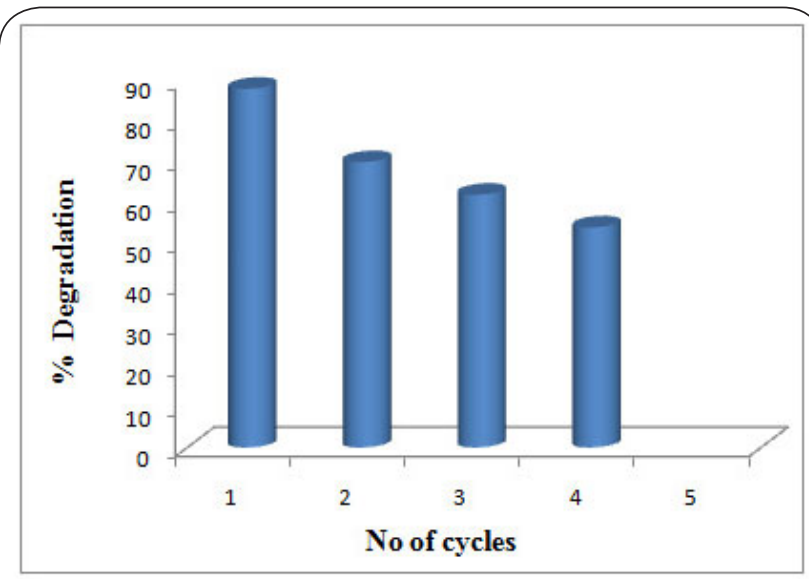

Figure 11. Recyclibility of Photocatalyst.

catalyst and loss due to repeated acid wash.

\section{Conclusion}

The results of this study have shown that the degradation of different textile dyes was successfully carried out in laboratory scale photo reactor containing coated $\mathrm{TiO}_{2}$ as photo catalyst. The experimental results showed that the rate of degradation depends on the chemical structure of different dyes as well as surface adsorption of dyes by $\mathrm{TiO}_{2}$ which is directly proportional to the surface area and dispersion of the catalyst, the adsorption of light by the dye. The COD decreases slower than the discoloration of the solution. The use of $\mathrm{TiO}_{2}$ coated on alginate could be a promising method as it can avoid the tedious final filtration of Titania in slurries and permit the photocatalyst recycling. Calcium alginate can be used as a green support for immobilizing $\mathrm{TiO}_{2}$ nanoparticles and can be used for developing a new environment friendly immobilization system for large scale water treatment. Also the commercial potential of this technique as an economic means of treating dye house effluent is very high.

\section{Competing interests}

The authors declare that they have no competing interests.

Authors' contributions

First author contributed in conception, research design, data interpretation and manuscript draft. Second and third authors contributed to fulfill the experiments and analyses, data interpretation and drafting the manuscript. Publication history

Received: 15-Dec-12 Revised: 22-Jan-2013

Accepted: 19-Feb-2013 Published: 05-Mar-2013

\section{References}

1. Robinson T, McMullan G, Marchant R and Nigam P: Remediation of dyes in textile effluent: a critical review on current treatment technologies with a proposed alternative. Bioresour Technol 2001, 77:247-55. I Article I PubMed

2. Mahmoud E K: Chemically enhanced primary treatment of textile industrial effluents. Polish Journal of Environmental studies 2009, 18: 651-655.

3. Kim S, Park C, Kim TH, Lee J and Kim SW: COD reduction and decolorization of textile effluent using a combined process. J Biosci Bioeng 2003, 95:102-5. I Article I PubMed

4. O'Neill C, Hawkes F R, Hawkes D L, Lourenco N D, Pinheiro H M and Wouter Delée: Colour in textile effluents-sources, measurement, discharge consents and simulation: a review. J. Chem. Technol. Biotechnol 1999, 74:10009-10018. I Article

5. Harikumar P S and Bindhya Mol K: A synoptic study on the preparation of a liquid waste management plan for Kerala state, India. Environment and Natural Resources Research 2012, 2:74-83. I Article

6. Gong R, Li M, Yang C, Sun Y and Chen J: Removal of cationic dyes from aqueous solution by adsorption on peanut hull. $J$ Hazard Mater 2005, 121:247-50. I Article I PubMed

7. Dave R S and Patel A R: Photochemical and photocatalytic of cypermethrin under UV radiation. Der pharma chemical 2010, 2:152158. I PDF

8. Iqbal MJ and Ashiq MN: Adsorption of dyes from aqueous solutions on activated charcoal. J Hazard Mater 2007, 139:57-66. | Article | PubMed

9. Kanan $\mathrm{N}$ and Sundaram M M: Kinetics and mechanism of removal of methylene blue by adsorption on various carbons a comparative study. Dyes and pigment 2001, 51: 25-40. | $\underline{\text { Article }}$

10. Arami M, Limaee NY, Mahmoodi NM and Tabrizi NS: Removal of dyes from colored textile wastewater by orange peel adsorbent: equilibrium and kinetic studies. J Colloid Interface Sci 2005, 288:3716. | Article | PubMed

11. Saad S A, Daud S, Kasim F H and Saleh M N: Metylene blue removal from simulated wastewater by adsorption using treated oil palm empty fruit bunch. $2007: 293-296$. I PDF

12. Al-Momani F, Touraud E, Degorce-Dumas J, Roussy J and Thomas $\mathrm{O}$ : Biodegradability enhancement of textile dyes and textile wastewater by UV photolysis. Journal of photochemistry and Photobiology A: Chemistry 2002, 153: 191-197. | PDF

13. Behnajady MA and Modirshahla N: Kinetic modeling on photooxidative degradation of C.I. Acid Orange 7 in a tubular continuous-flow photoreactor. Chemosphere 2006, 62:1543-8. Article I PubMed 
Harikumar et al. Journal of Environmental Engineering \& Ecological Science 2013, http://www.hoajonline.com/journals/pdf/2050-1323-2-2.pdf

14. Khataee AR, Pons MN and Zahraa O: Photocatalytic degradation of three azo dyes using immobilized TiO2 nanoparticles on glass plates activated by UV light irradiation: influence of dye molecular structure. J Hazard Mater 2009, 168:451-7. | Article I PubMed

15. Gupta Shipra Mital AND Tripathi Manoj: A review of $\mathrm{TiO}_{2}$ nanoparticles. Chinese Science Bulletin 2011, 56: 1639-1657. | Article

16. Harikumar P S and Litty Joseph: Kinetic and thermodynamics studies of as (III) adsorption onto iron nanoparticles entrapped ca-alginate beads. International Journal of Plant, Animal and Environmental Sciences 2012, 2:159-156.

17. Santos D T, Sarrouh B F, Rivaldia J D, Converti A and Silva S S: Use of sugarcane bagasse as biomaterial for cell immobilization for xylitol production. J. Food Eng 2008 86:542-548. | Article

18. Juliana A H, Paridah M T, Rahim S, Nor Azowa I and Anwar U M K: Production of particleboard from kenaf (Hibiscus cannabinusL.) as function of particle geometry. Matter. Design 2012, 34: 406-411.

19. Harikumar P S, Litty Joseph and Manjusha C M: Bio synthesis of silver nanoparticles and its application in microbial treatment of drinking water. Nano Science and Nano Technologyy 2011, 5:23-27.

20. Margaret E Lyn and DanYang Ying: Drying model for calcium alginate beads. Ind. Eng. Chem. 2010, 49: 1986-1990. | Article

21. Cheng H, Ma J, Zhao Z and Qi L( 1995) Hydrothermal preparation of uniform nanosize rutile and anatase particles. Chem. Mater 1995, 7:663-671. | Article

22. Sakthivel S, Shankar MV, Palanichamy M, Arabindoo B, Bahnemann DW and Murugesan V: Enhancement of photocatalytic activity by metal deposition: characterisation and photonic efficiency of Pt, Au and Pd deposited on TiO2 catalyst. Water Res 2004, 38:3001-8. | Article I PubMed

23. Bouzaida I, Ferronato, Chovelon J M, Rammah M E and Hermann J M: Photocatalytic degradation of the anthraquinonic dye, Acid Blue (AB25): a kinetic approach.J. Photochem.Photobiol. A: Chem. 2004, 168:23-30. | Article

24. Arslan I, Balcioglu I A and Bahnemann DW: Heterogeneous photocatalytic treatment of simulated dyehouse effluents using novel $\mathrm{TiO}_{2}$-photocatalysts. Applied Catalysis B-Environmental 2000 26:193-206. | Article

25. Barka N, Qourzal S, Assabbane A, Nounah A and Ait-lchou Y: Factors influencing the photocatalytic degradation of Rhodamine $\mathrm{B}$ by $\mathrm{TiO}_{2}$ coated non-woven paper. J. Photochem. Photobiol.A: Chem 2008, 195:346-351. | Article

\section{Citation:}

Ps H, Joseph L and A D: Photocatalytic degradation of textile dyes by hydrogel supported titanium dioxide nanoparticles. journal of Environmental Engineering and Ecological Science 2013, 2:2.

http://dx.doi.org/10.7243/2050-1323-2-2 